\title{
An adhesive CFD-DEM model for simulating nanoparticle fluidization
}

\author{
Daoyin Liu ${ }^{1,2}$, Berend G. M. van Wachem³ ${ }^{3}$ Robert F. Mudde², Xiaoping Chen ${ }^{1}$, J. Ruud van Ommen²* \\ * Corresponding author. Telephone: +31 15278 2133. E-mail address: j.r.vanommen@tudelft.nl \\ 1 Key Laboratory of Energy Thermal Conversion and Control of Ministry of Education, School of Energy and Environment, \\ Southeast University, Nanjing 210096, Jiangsu, China \\ 2 Department of Chemical Engineering, Faculty of Applied Sciences, Delft University of Technology, Julianalaan 136, 2628 BL \\ Delft, The Netherlands \\ 3 Thermofluids Division, Department of Mechanical Engineering, Imperial College London, London, United Kingdom
}

\section{Abstract}

Nanoparticle fluidization is an efficient technique to disperse and process nanoparticles. Previous studies show that nanoparticles are not fluidized individually, but as agglomerates with hierarchical fractal structures. In this study, an adhesive CFD-DEM (Computational Fluid Dynamics - Discrete Element Modelling) model is developed, in which we use the simple agglomerate as the discrete element, which are the building blocks of the larger complex agglomerates found in a fluidized bed. We show that both the particle contact model and drag force interaction in the conventional CFD-DEM model need modification for properly simulating fluidization of nanoparticle agglomerates. The contact model includes collision mechanisms of elastic-plastic, cohesive and viscoelastic forces, and the drag force is approximately corrected by a scale factor resulting from particle agglomeration. The model is tested for different cases, including the normal impact, response of angle, and fluidization. The simulation results are promising. With increasing particle cohesive force, the fluidized bed goes from a uniform fluid-like regime, to an agglomerate bubbling regime, and finally to defluidization. The current study provides a tool for gaining insights into the characteristics of nanoparticle fluidization.

Keywords: Nanoparticle Fluidization, Agglomerate, Discrete Element Model; Adhesion

\section{Introduction}

Nanoparticle fluidization has attracted increasing attention in the past decade, as a promising technique to disperse and process nanoparticles (van Ommen et al., 2012). The structure of nanoparticle agglomerates formed during fluidization have been studied extensively. It is known that nanoparticles are not fluidized individually but as agglomerates: very dilute clusters of around a few hundreds of micrometres (de Martín et al., 2014a; Hakim et al., 2005; Valverde and Castellanos, 2008; Wang et al., 2002). The macroscopic behavior of nanoparticle fluidized bed can have two different appearances: the bed expands highly and homogeneously without obvious bubbles (APF type), or the bed expands slightly with significant bubbles ( $A B F$ type). Especially $A B F$ type beds often require an assistance method to obtain proper fluidization; examples of such methods are electric fields, vibration, micro-jets, and sound waves. (Lepek et al., 2010; Matsuda et al., 2004; Quevedo et al., 2010; Zhu et al., 2004). Studies of nanoparticle fluidization are often limited to macroscopic properties (Huang et al., 2008; Tamadondar et 
al., 2014). Detailed flow characteristics inside the fluidized beds, e.g., gas/solid volume fraction, velocity distribution, gas/solid mixing, are difficult to obtain due to inherent difficulties in their measurement.

Numerical simulation (e.g., Euler-Euler model and Euler-Lagrange model) has become an essential tool to access detailed flow characteristics of the conventional fluidized beds with Geldart group B/D/A particles. Particularly for Geldart A particles, efforts have been made to model particle adhesion due to van der Waals (vdW) forces (Galvin and Benyahia, 2014; Kobayashi et al., 2013; Motlagh et al., 2014; van Wachem and Sasic, 2008; Wang et al., 2011). For modelling nanoparticle fluidization, the model complexity increases further, because the nanoparticle agglomerates are not only cohesive (Salameh et al., 2014), but they show plasticity (Schilde and Kwade, 2012) and they break and recombine continuously (Hakim et al., 2005).

In this study, we have developed a model based on CFD-DEM model (Computational Fluid Dynamics - Discrete Element Modelling) (Deen et al., 2007; Tsuji et al., 1993; Zhu et al., 2007), where the motion of each particle element is determined by Newton's second law. It has proven to be a successful tool for studying conventional fluidized beds in literature (He et al., 2012; Luo et al., 2014; van Wachem et al., 2001; Yang et al., 2014; Zhong et al., 2006). For simulating nanoparticle fluidization, as the particle element we use fragments of the large, complex agglomerates present in the bed: the so-called simple agglomerates. Our idea came from the viewpoint of agglomerates presented by de Martín et al. (2014a), which is based on a series of previous studies (de Martín et al., 2014b; Gundogdu et al., 2007; Hakim et al., 2005; Valverde and Castellanos, 2008; Wang et al., 2006; Wang et al., 2002). Nanoparticles agglomerates have a multi-stage structure: aggregates of nanoparticles sintered during production ( 200 $\mathrm{nm})$, the simple agglomerates, and complex agglomerate. During fluidization the complex agglomerates (200-400 $\mu \mathrm{m})$ are in a dynamic balance of congregating and separating of the simple agglomerates. The size of the simple agglomerates is usually around 5-45 $\mu \mathrm{m}$ (de Martín et al., 2014a). To avoid too heavy computation, the size of the simple agglomerate size (briefly referred as DEM particle in the following) is chosen as $40 \mu \mathrm{m}$.

In literature, there are a few studies trying to model nanoparticle fluidization by assuming complex agglomerates as particle (Bahramian et al., 2013; Wang et al., 2008). By treating the simple agglomerate as the DEM particle, one advantage is that we do not need to model particle fragmentation. Additionally, mechanical properties of the nanoparticle agglomerates whose size similar to the simple agglomerates can be obtained from literature (Schilde and Kwade, 2012) and on-going studies in our research group. Furthermore, the size of the simple agglomerates is similar to Geldart A particles, which allow us to learn from successful experiences of the simulation studies on fluidization of Geldart A particles. The disadvantage of this approach is that the computational load is quite heavy, which limits the simulation scale. 
The objective of this paper is to present and test a model that realistically describes the influence of agglomerate dynamics on nanoparticle fluidized beds, while taking into account that it is computationally impossible to consider all individual nanoparticles. In the following, a detailed description of the CFDDEM model for nanoparticle fluidization is presented. Then it is tested for different simulation cases regarding normal impact, response of angle, and fluidization.

\section{Model}

The current model, which we will denote as the adhesive CFD-DEM model, is a combination of the standard CFD-DEM model, an adhesive contact model and a drag force correction method. It is implemented in MultiFlow, a parallel multi-phase flow solver (van Wachem, 2013). A detailed description of the standard CFD-DEM model can be referred in the literature (Deen et al., 2007; Liu et al., 2013; Mallouppas and van Wachem, 2013). The motion of the gas phase is calculated by local averaged NavierStokes equations while the motion of each particle is calculated by Newton's second law. The interaction between the particles is usually modelled by a simplified contact model, and the interaction between the gas and particles is modelled by a semi-empirical drag model.

\subsection{Adhesive contact model}

Several adhesive contact models for fine and ultrafine particles have been proposed in literature, mostly in the field of granular systems. Tomas (2007) developed a realistic force-displacement model for the elastic-plastic, adhesive and frictional contact. Luding (2008) developed a simplified linear contact model involving the elastic-plastic and adhesion contact. Marshall (2009) and Li et al. (2011) developed an adhesive contact model by combing the JKR contact model (Johnson et al., 1971) and the viscoelastic effect. In the field of fluidization, it is commonly proposed to add linearly the vdW force and the elastic force (Galvin and Benyahia, 2014; Ye et al., 2004).

Experimental measurements on nanoparticle agglomerates using Atomic Force Microscope (AFM) (Salameh et al., 2014) and nanoindentation (Raichman et al., 2006; Schilde and Kwade, 2012) showed that they are adhesive, and behave as elastic-plastic particles. Significant hysteresis of the forcedisplacement curves is observed when a nanoparticle agglomerate approaches and detaches with a substrate. The contact model we use is a modification of Luding's model. The modifications include the estimation method of the maximum cohesive force and the particle breakoff mode. Additionally, the viscoelastic force is included. The involved contact mechanisms include the elastic-plastic deformation, cohesive and viscoelastic dissipation, and friction. The contact model is described in detail in the following.

Let us consider the configuration that a spherical simple nanoparticle agglomerate (referred as DEM particle) collides with a flat wall. Figure 1 shows the schematic of the force-displacement curve of the adhesive contact model. Initially, the particle is located at a given separation distance from the wall, with 
an perpendicular velocity towards the wall. The separation distance between the particle and wall is noted as $d(t)$, thus particle deformation is $\delta=-d(t)$. Four different stages can be distinguished during the contact: approach, loading, unloading, and detachment.

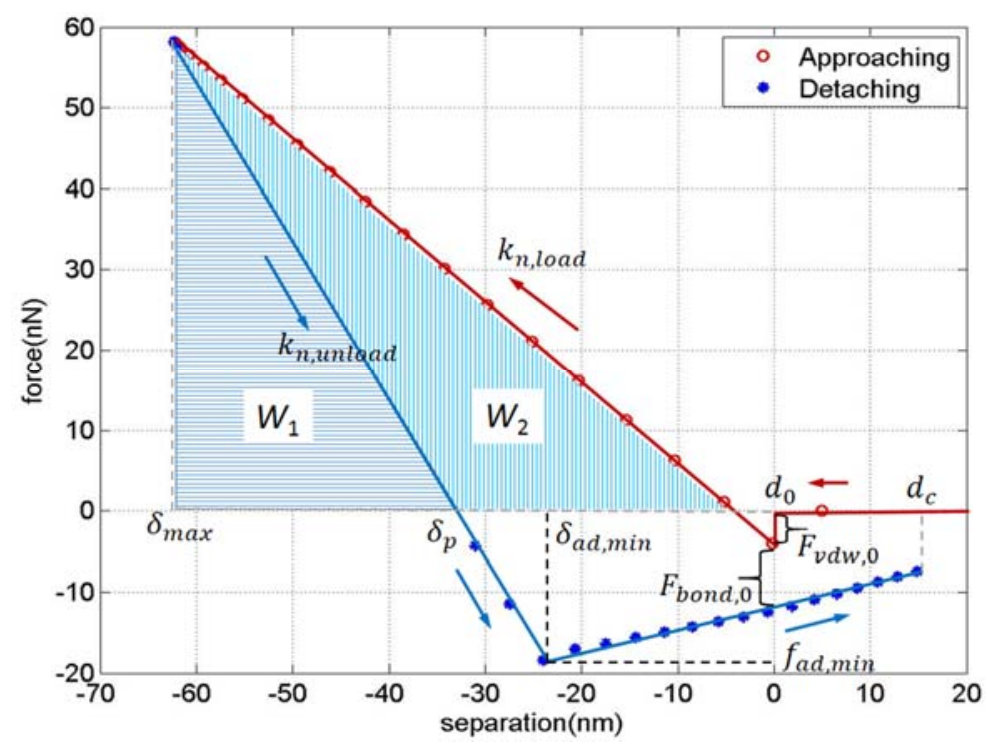

Figure 1 Schematic of the force-displacement curve of the adhesive contact model. It is a modification of Luding's model (Luding, 2008)

During the approach stage, the cohesive force is zero when the separation distance is larger the minimal separation distance $\left(H_{0}\right)$ :

$$
\mathrm{F}_{\mathrm{n}}(d)=0 \quad d(t)>H_{0}
$$

Although actually the cohesive force gradually decreases to zero when $d(t)>H_{0}$, a model sensitivity analysis shows the effect of $H_{0}$ and cohesive force during the approaching stage on the collision behavior is negligible. Therefore, $H_{0}$ is set as zero in the current model.

During the initial loading stage, the interaction is a combination of the spring force and vdW force:

$$
\mathrm{F}_{\mathrm{n}}(d)=k_{n, \text { load }} \delta_{n}-F_{v d w, 0}
$$

where $F_{v d w, 0}$ is $\mathrm{vdW}$ force at the minimal separation distance, $k_{n, l o a d}$ the loading stiffness, and $\delta_{n}$ the normal deformation. As the loading proceeds, the history of $\delta_{n}$ is saved and the maximum $\delta_{n}$ is kept. During the unloading stage, the interaction is a combination of the spring force and vdW force. The other cohesive forces which result from physical or chemical adsorption, e.g., the hydrogen bond force, can also be added during the unloading stage. We included the hydrogen bond force in the Eq. (3), but we will set it to zero in the simulations in order to focus the discussion on the vdW force in this paper.

$$
\mathrm{F}_{\mathrm{n}}(d)=\left\{\begin{array}{cl}
k_{n, \text { unload }}\left(\delta_{n}-\delta_{p}\right)-F_{v d w, 0} & \mathrm{~F}_{\mathrm{n}} \geq f_{a d, \text { min }} \\
\left(1-x_{1}\right)\left(-F_{v d w, 0}-F_{b o n d, 0}\right)+x_{1} f_{a d, \text { min }} & \mathrm{F}_{\mathrm{n}}<f_{a d, \text { min }}
\end{array}\right.
$$


where $k_{n \text {,unload }}$ is the unloading stiffness, $\delta_{p}$ the permanent plastic deformation, and $F_{H b o n d, 0}$ the bond force at minimal separation distance, $x_{1}$ a linear interpolation fraction between $d=0$ and $d=\delta_{a d \text {, min }}$. The maximum magnitude of the cohesive force is limited by $f_{a d, \min }$. These parameters are determined by the following equations:

$$
\begin{gathered}
\psi_{p}=k_{n, \text { load }} / k_{n, \text { unload }} \\
\delta_{p}=\left(1-k_{n, \text { load }} / k_{n, \text { unload }}\right) \delta_{\max } \\
f_{a d, \text { min }}=\left(\delta_{0} / d_{p, N P}+1\right)\left(-F_{v d w, 0}-F_{H b o n d, 0}\right)
\end{gathered}
$$

Where is $\psi_{p}$ is plasticity index, and $d_{p, N P}$ the size of the primary nanoparticle.

During the detach stage, the cohesive force still exists until $d(t)<d_{c}$, which is the break-off distance. At $d_{c}$, the interaction breaks off suddenly. $d_{c}$ and the fraction of cohesive force magnitude at $d_{c}$ are suggested by JKR model (Johnson et al., 1971).

$$
\begin{aligned}
\mathrm{F}_{\mathrm{n}}(d)= & \left(1-x_{2}\right)\left(-F_{v d w, 0}-F_{H b o n d, 0}\right) \\
& +5 / 9 x_{2}\left(-F_{v d w, 0}-F_{H b o n d, 0}\right)
\end{aligned}
$$

where $x_{2}$ is a linear interpolation fraction between $d=0$ and $d_{c}$.

In some conditions, the particle is reloaded again during the unloading or detach stage. During the reloading stage, the spring force follows the unloading stiffness.

Eqs. (1) to (5) give the force during a quasi-static contact. For a dynamic impact, the viscoelastic force is added. Finally, the normal component of the contact force between a pair of particles is as following:

$$
\mathbf{F}_{\mathrm{ab}, \mathbf{n}}=-\mathrm{F}_{\mathrm{n}}(d) \mathbf{n}_{\mathrm{ab}}-\eta_{n} \mathbf{v}_{\mathrm{ab}, \mathbf{n}}
$$

where $\mathbf{v}_{\mathrm{ab}, \mathbf{n}}, \mathbf{n}_{\mathbf{a b}}$, and $\eta_{n}$ are the relative velocity, unit vector, and damping coefficient along the normal director.

The tangential component of the contact force is calculated as usual:

$$
\mathbf{F}_{a b, t}= \begin{cases}-k_{t} \boldsymbol{\delta}_{t}-\eta_{t} \mathbf{v}_{\mathbf{a b}, \mathbf{t}} & \mathbf{F}_{a b, t}>\mu_{f}\left|\mathbf{F}_{a b, n}\right| \\ -\mu_{f}\left|\mathbf{F}_{a b, n}\right| \mathbf{t}_{a b} & \mathbf{F}_{a b, t}>\mu_{f}\left|\mathbf{F}_{a b, n}\right|\end{cases}
$$

where $\mathbf{v}_{\mathrm{ab}, \mathbf{t}}, \mathbf{t}_{\mathrm{ab}}$, and $\eta_{t}$ are the relative velocity, unit vector, and damping coefficient along the tangential director.

The damping coefficient is determine by the viscoelastic coefficient of restitution:

$$
\eta_{n(t)}=2 \sqrt{m_{a b} k_{n(t)}} \ln e_{v i s} / \sqrt{\pi^{2}+\ln ^{2} e_{v i s}}
$$

Eqs. (1) to (8) constitute a complete adhesive contact model. There are together 8 input parameters: $e_{v i s}$, $k_{n, \text { unload }}, \psi_{p}, F_{v d w, 0}, F_{H b o n d, 0}, d_{p, N P}, d_{c}$, and $\mu_{f}$. 


\subsection{Drag force scale factor}

When particles are agglomerated, the particles inside the agglomerate hardly experience the gas flow, which can be expressed as a reduction of the inter-phase surface. Therefore, the drag force on the solid phase is reduced. In simulations of fluidization of Geldart A particles, it is common practice to use a scale factor for drag force (Li et al., 2008; Wang et al., 2011) or an agglomerate diameter instead of the original particle diameter (Seo et al., 2014; Wang et al., 2013; Zeidan and Okasha, 2014). McKeen and Pugsley (2003) scaled the drag force by a factor of $0.2-0.3$ for FCC particles with diameter of $75 \mu \mathrm{m}$. Such a scale factor corresponds to an effective agglomerate diameter in the range 135-170 $\mu \mathrm{m}$. van Wachem and Sasic (2008) used an alternative approach: instead of setting the scale factor directly, they developed a force balance model of a single particle and predicted the agglomerate size locally. This idea was adopted by Motlagh et al. (2014) who developed a dynamic agglomerate structure-based drag force correction model for simulating Geldart A particles.

Similar to the studies on fluidization of Geldart A particles, we introduce a drag force scale factor $(\xi)$ on fluidization of nanoparticles. It is defined by

$$
\xi \equiv f_{d, p} / f_{d, 0}=\left(f_{d, a g g} / n_{p}\right) / f_{d, 0}
$$

where $f_{d, 0}, f_{d, p}$, and $f_{d, a g g}$ respectively represent drag force on a single isolated particle, drag force on a single particle belonging to an agglomerate, and drag force on an agglomerate. $n_{p}$ is particle number of an agglomerate. It is assumed that the agglomerate is homogenous, spherical, and impermeable. $f_{d, 0}$ and $f_{d, a g g}$ can be calculated using a semi-empirical drag equation, e.g., Wen and Yu drag model. For example, the particle (simple agglomerate) number $n_{p}$ is expressed as $n_{p}=\left(d_{\text {agg }} / d_{p}\right)^{D_{f}}$ in a complex agglomerate (de Martín et al., 2014b). As shown in Figure 2, as $d_{\text {agg }}$ increases, $n_{p}$ increases with increasing slope, while the drag force increases nearly linearly. This will lead to a great reduction of the drag force on each single DEM particle. 


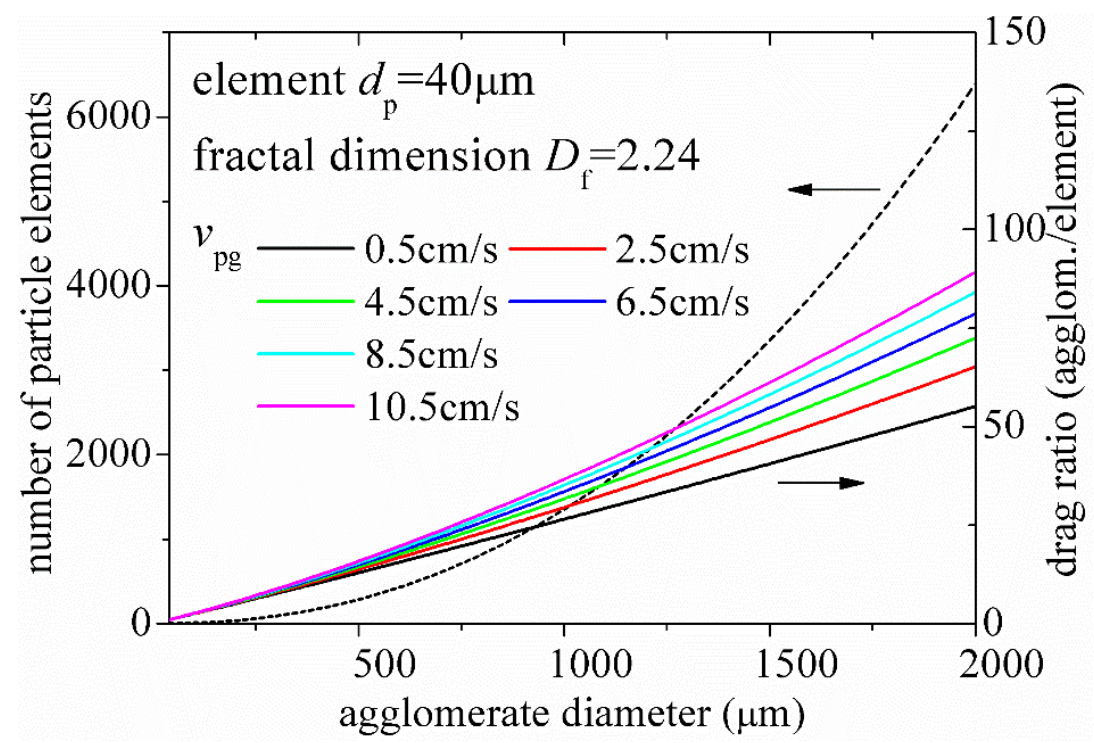

Figure 2 Effect of agglomerate diameter on number of particle elements and drag force

\subsection{Computational algorithm}

Figure 3 gives a schematic of the adhesive CFD-DEM model. The general algorithm at each time step is similar to the standard CFD-DEM model, but the contact model is substituted by the adhesive contact model and the drag force is multiplied by the scale factor $(\xi)$.

Because the value of $\xi$ is not known before simulation, we adopt a "predictor-corrector method" which is often used in numerical computational study. First the simulation is performed using a predictor of $\xi$, then the results at different time instants are analyzed to extract the averaged agglomerate information, based on which the corrector of $\xi$ is calculated using Eq. (12). The simulation is repeated until the predictor and corrector converge. Based on our computational experience, a few iterations usually reasonable convergence.

It should be noted that by this approach the drag force reduction is estimated approximately. It is extremely challenging to accurately calculate drag force on agglomerates in the context of a whole fluidized bed, which is not attempted in the current paper. Another point that should be noted is the identification of agglomerates. In this paper, DEM particles in contact, whose relative velocity is smaller than 1 e-3 $\mathrm{m} / \mathrm{s}$ and coordination number larger than 2, are recognized as agglomerates. We realize that many other criteria are possible for agglomerate identification; an evaluation of various criteria is currently ongoing in our group. The current search of contacts is performed using a Last In First Out (LIFO) data structure, which is described in Appendix A. 


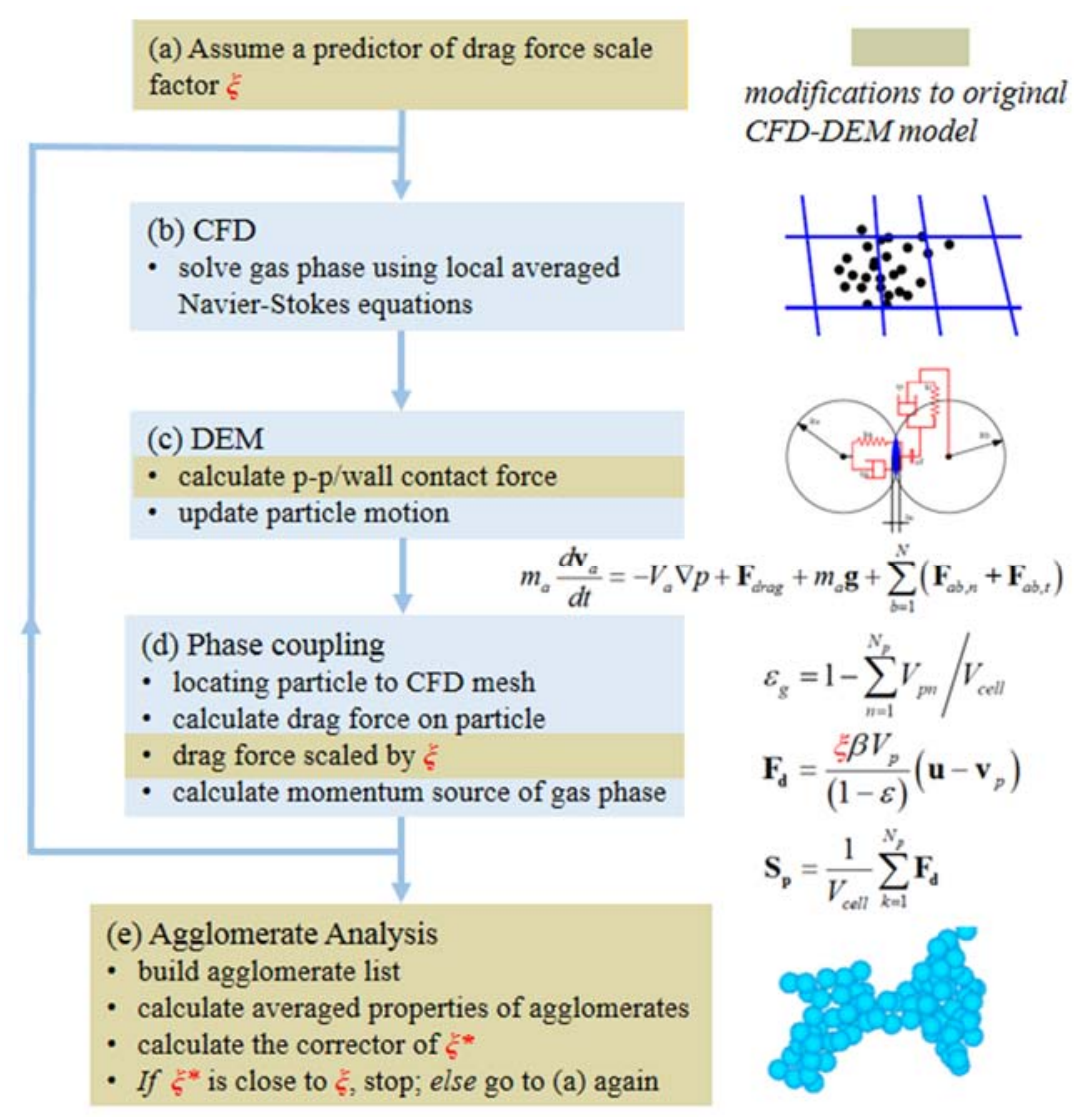

Figure 3 Schematic of the adhesive CFD-DEM model

\section{Results and Discussion}

With increasing adhesion and plasticity, particles tend to stick to each other, which can significantly affect fluidization characteristics. Before simulating fluidized beds, two test cases are used to investigate the model's ability of predicating particle adhesion, which are the normal impact and response of angle. In the normal impact case, the impact of a single particle impacting on a flat surface is investigated. In the response of angle case, a granular system naturally sliding on a horizontal surface is investigated. Finally, we simulated fluidized beds, in which the motion of both the particles and gas phase are calculated. The system properties of the latter two cases are given in Table 1.

Table 1 System properties of the test cases

\begin{tabular}{|c|c|c|c|}
\hline parameter & unit & response of angle case & fluidized bed case \\
\hline particle properties & & \multicolumn{2}{|c|}{ simple nanoparticle agglomerate, refer to Table 2} \\
\hline Dimensions $[\mathrm{x}, \mathrm{y}, \mathrm{z}]$ & $\mathrm{mm}$ & {$[4,4,4]$} & {$[4,20,0.8]$} \\
\hline particle number & - & 30,000 & $\sim 199,000$ \\
\hline fluid/DEM $\Delta t$ & $\mathrm{~S}$ & 1e-6 & $1 \mathrm{e}-5 / 1 \mathrm{e}-6$ \\
\hline
\end{tabular}




\subsection{Test case: Normal impact}

First we consider a normal particle/surface collision configuration, where the restitution coefficient $(e)$ and critical velocity $\left(v_{c t}\right)$ can be obtained from the particle trajectory during collision. $e$ is the ratio between the particle velocities after and before impact. $v_{c t}$ is the critical point below which the impacting particles stick together. However, to date there is very limited published experimental data on collision of the nanoparticle agglomerates. Thus, the validation is split into two separate cases: in the first case, energy dissipation is caused by the viscoelastic and cohesive forces; in the second case, energy dissipation is caused by the plastic deformation.

For the first case, the rebound behaviors of the ultrafine Molybdenum particles (2-7 $\mu \mathrm{m}$ diameter) at the lower collision impact velocities by Wall et al. (1990) are used for comparison, where the particle adhesion is mainly caused by vdW force. Figure 4(a) shows the variation of $e$ with the impact velocity $v_{i}$ ( $e \sim v_{i}$ curve) at different particle sizes. The agreement is quite good: the $e \sim v_{i}$ curve has a steep increase around the stick point; $e$ stays nearly constant with further increasing velocity due to the impulse force is dominant. Moreover, the influence of the cohesive force is stronger with decreasing particle size. In the modelling, the fraction of the viscoelastic energy dissipation is constant at 0.8 . The stiffness is a fitted value; it is smaller for the finer particles. The adhesion force is determined from the adhesion work, which is $0.34 \mathrm{~J} / \mathrm{m}^{2}$ for the Molybdenum particles (Li et al., 2011).

For the second case of collision with the plastic deformation, the rebound behaviors of $\mathrm{mm}$-sized granules by Antonyuk et al. (2006) are used for comparison, as shown in Figure 4(b). In this case, the viscoelastic and cohesive forces are set to zero. The model is thus simplified to the model of Walton and Braun (1986), where the restitution coefficient only depends on the plasticity index.

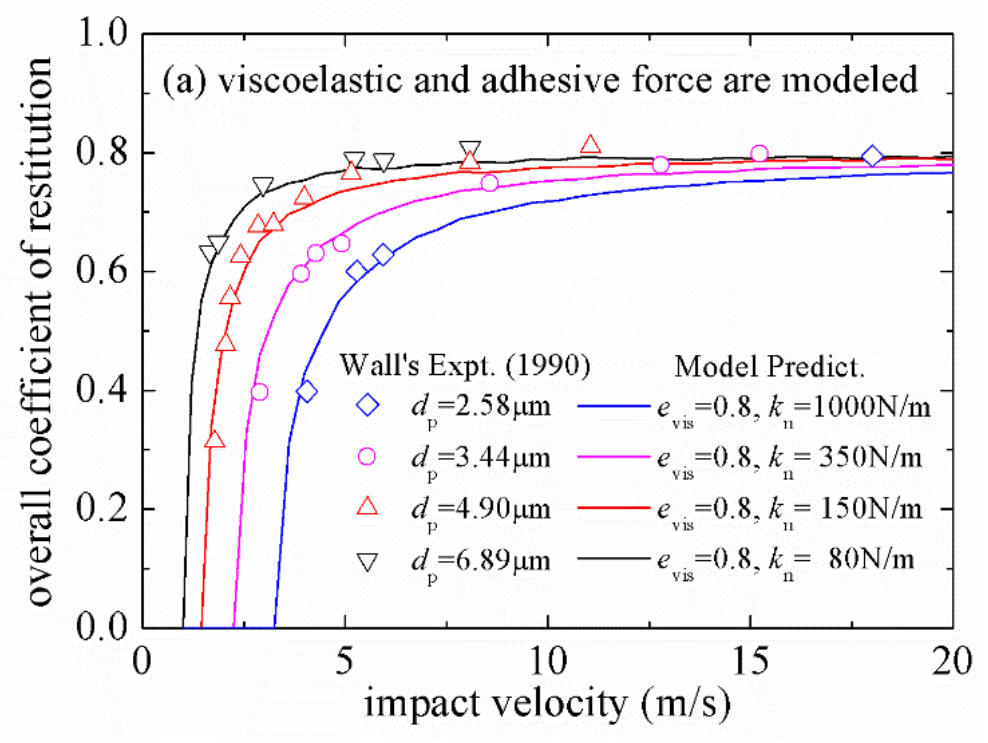




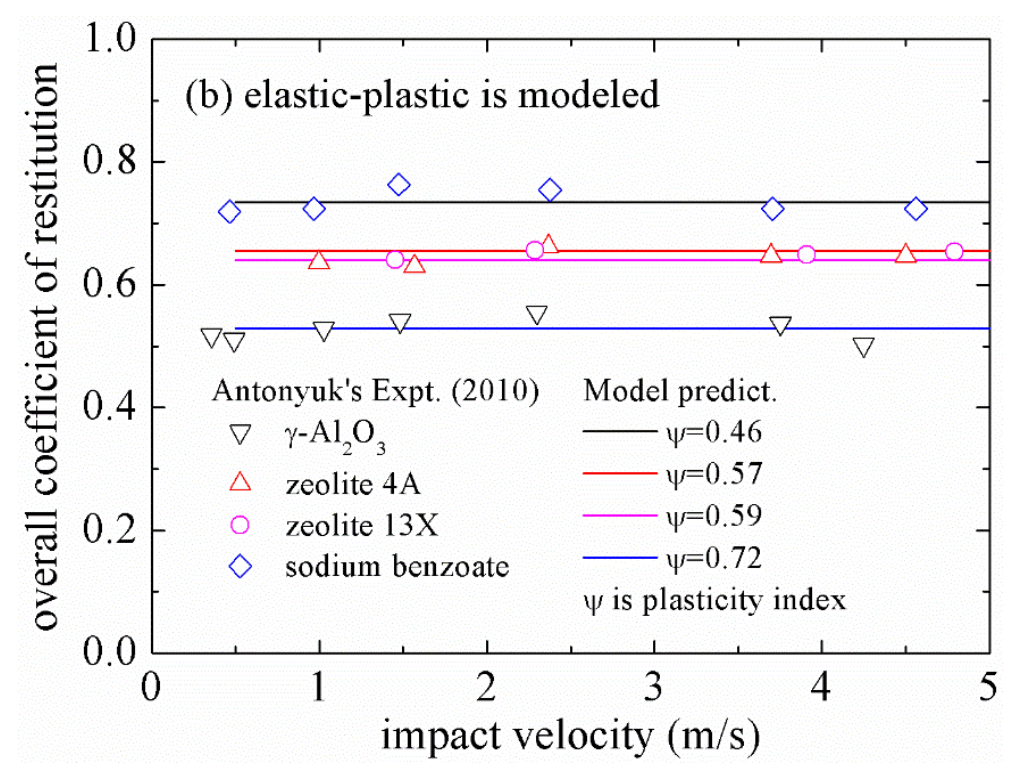

Figure 4 Coefficient of restitution versus normal impact velocity: (a) model with viscoelastic and cohesive forces; (b) model with plastic energy dissipation

Next we consider collision of the nanoparticle agglomerates. Based on experimental measurements performed in nanoparticle fluidized bed (de Martín et al., 2014b), the agglomerate size is chosen as 40 $\mu \mathrm{m}$, and the agglomerate density is $250 \mathrm{~kg} / \mathrm{m}^{3}$. The ranges of the cohesive forces, stiffness, and plasticity index are estimated using the experimental data in the literature. Based on force analysis by de Martín and van Ommen (2013), the vdW force between agglomerates is 2-10 nN. Kendall and Weihs (1992) derived a formula for the Young's modulus of the agglomerates, which is a function of porosity, primary particles, and surface energy. Based on this formula the Young's modulus is estimated around the order of $100 \mathrm{KPa}$ for the nanoparticle agglomerates. Correspondingly, the stiffness is around the order of $1 \mathrm{~N} / \mathrm{m}$. Based on the nanoindentation measurements by Schilde and Kwade (2012), the plasticity index of the nanoparticle agglomerates is varied between 0.2 and 0.5 . A summary of the properties chosen for the present DEM particle element (the simple nanoparticle agglomerate) is listed in Table 2.

Table 2 Properties of DEM particle (the simple agglomerate)

\begin{tabular}{|c|c|c|c|c|}
\hline parameter & symbol & Value & unit & Reference \\
\hline DEM particle diameter & $d_{p}$ & 40 & $\mu m$ & \multirow{2}{*}{$\begin{array}{c}\mathrm{TiO}_{2}, d_{p, N P}=20 n m \text {, } \\
\text { (de Martín et al., 2014b) }\end{array}$} \\
\hline DEM particle density & $\rho_{p}$ & 250 & $\mathrm{~kg} / \mathrm{m}^{3}$ & \\
\hline Particle gravity force & $m g$ & 0.082 & $\mathrm{nN}$ & \\
\hline Terminal velocity & $u_{t}$ & 6.78 & $\mathrm{~cm} / \mathrm{s}$ & \\
\hline Viscoelastic COR & $e_{v i s}$ & 0.8 & & usually $0.8 \sim 0.9$ \\
\hline$F_{v d w, 0} / m g$ & $B o_{v d w}$ & $0-100$ & & $\begin{array}{c}\text { (de Martín and van } \\
\text { Ommen, 2013) }\end{array}$ \\
\hline
\end{tabular}




\begin{tabular}{|l|c|c|c|c|}
\hline Spring stiffness (unloading) & $k_{n, \text { unload }}$ & $1.4-3.2$ & $N / m$ & $\begin{array}{c}\text { (Kendall and Weihs, } \\
\text { 1992) }\end{array}$ \\
\hline Plasticity index & $\psi_{p}$ & $0-0.5$ & & $\begin{array}{c}\text { (Schilde and Kwade, } \\
\text { 2012) }\end{array}$ \\
\hline Frictional coefficient & $\mu_{f}$ & 0.35 & & usually $\sim 0.3$ \\
\hline
\end{tabular}

The cohesive force $\left(B o_{v d w}\right)$, stiffness $\left(k_{n, \text { unload }}\right)$, and plastic index $\left(\psi_{p}\right)$ listed in Table 2 are varied to investigate their effects on the particle collision. Figure 5 shows the effect of the cohesive force on the critical velocity with different values of the stiffness and plasticity index. Clearly, the critical velocity increases with increasing cohesive force. Another an important observation is that the critical velocity also depends on the stiffness and plasticity. With the same cohesive force, decreasing the stiffness or increasing the plasticity can increase the critical velocity.
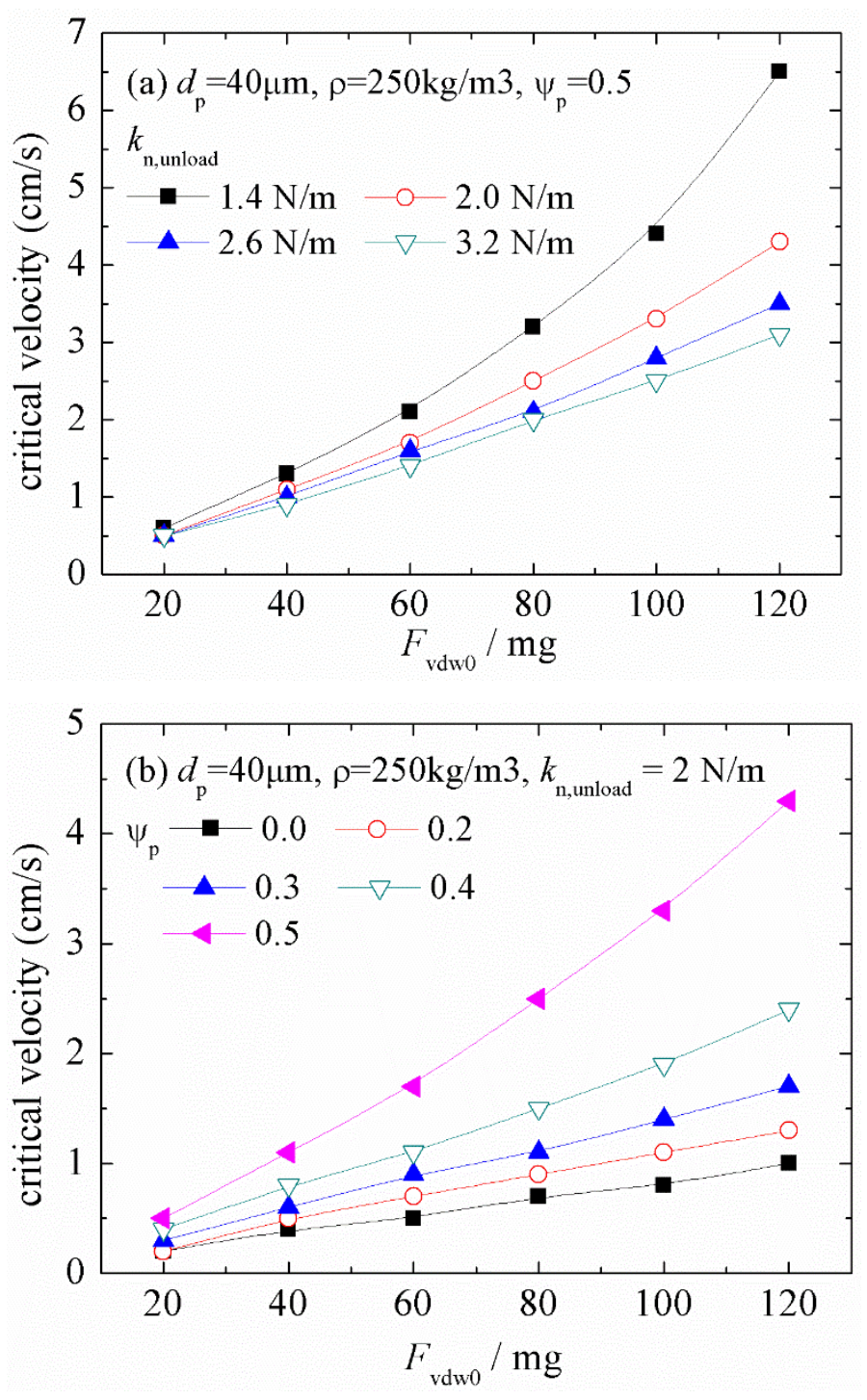

Figure 5 Critical velocity as a function of cohesive force at conditions with different values of (a) stiffness and (b) plasticity index 


\subsection{Test case: Response of angle}

Next, we consider the case of response of angle of a particle assembly. The angle of repose (AOR) is the maximum angle of a stationary particle assembly to a horizontal plane. An AOR below $30^{\circ}$ indicates good flowability, $30^{\circ}-45^{\circ}$ some cohesiveness, $45^{\circ}-55^{\circ}$ true cohesiveness, and $>55^{\circ}$ very high cohesiveness (Geldart et al., 2006).

Figure 6 shows the collapse snapshots under different cohesive forces. As expected, the AOR increases with increasing cohesive force. Figure 7 plots correlation between AOR and critical velocity. It is found that as the critical velocity increases, AOR increases. For a critical velocity larger than about 0.5 $\mathrm{cm} / \mathrm{s}$, the AOR exceeds $55^{\circ}$ indicating that the particles are very cohesive.

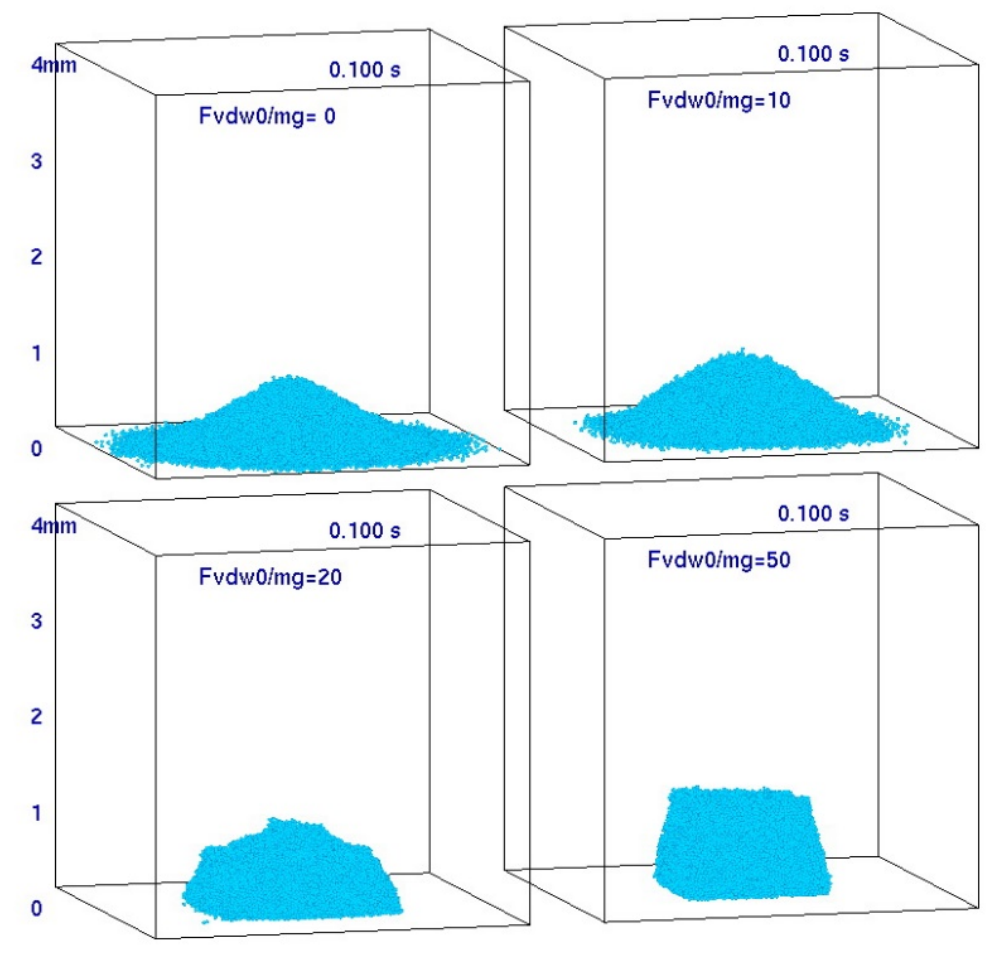

Figure 6 Response of a particle assembly under different adheisve forces 


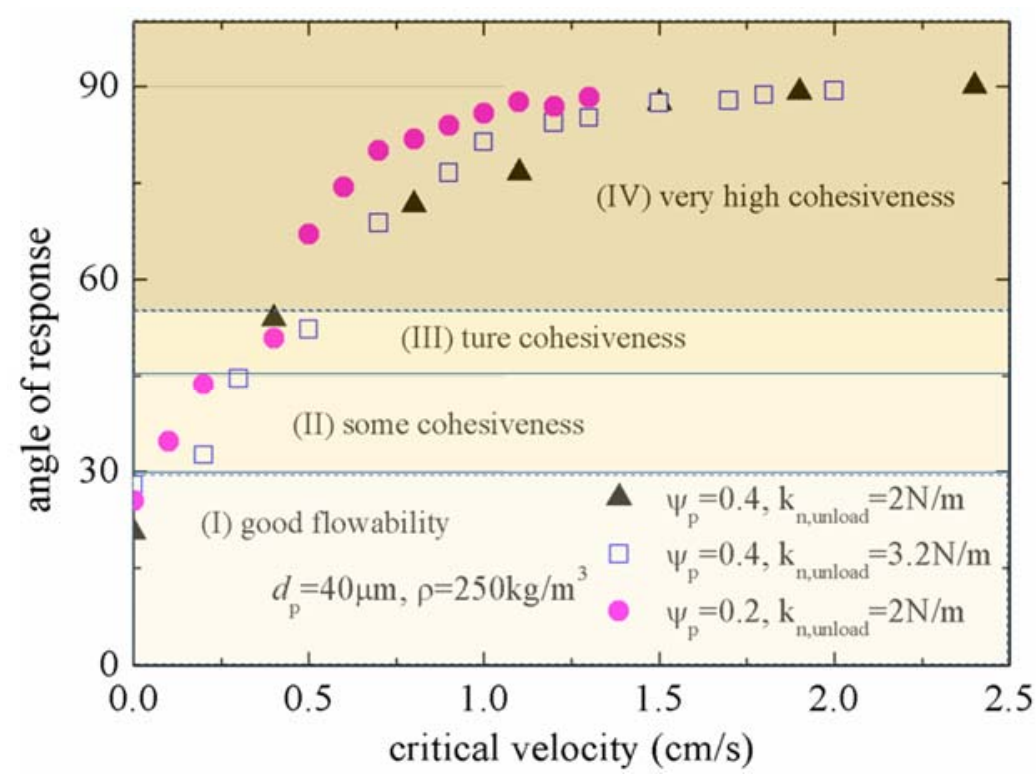

Figure 7 Correlation between the critical velocity and response of angle

\subsection{Test Case: Fluidized bed}

Finally, we turn to the case of a nanoparticle fluidized bed. The fluidizing gas velocity is fixed at a typical value of $2 \mathrm{~cm} / \mathrm{s}$ while $B o_{v d w}$ is varied at $0,20,50$, and 100. First, the drag force scale factor $\xi=$ 0.2 is used in all the simulation cases. The predicted particle flow patterns are shown in Figure 8. It is shown that the agglomerates become larger with increasing vdW force. However, the bed expansion ratio are similar under different $\mathrm{vdW}$ forces, because $\xi$ is the same in different cases.

The results at different time instants are analyzed to extract the averaged agglomerate information, which is listed in Appendix B. Based on the agglomerate analysis, the corrected $\xi$ is $0.60,0.22,0.13$, and 0.04 for $B o_{v d w}=0,20,50$, and 100, respectively. Then, the simulations are performed with the corrected $\xi$. The predicted particle flow patterns are shown in Figure 9. A significant difference from Figure 8 is that, the bed expansion ratio decreases significantly with increasing vdW force. For $B o_{v d w}=$ 50 and 100, defluidization takes place. Again, the agglomerates are analysed (listed in Appendix B) and the corrected values of $\xi$ are calculated, which are $\xi=0.56,0.25,0.03$, and 0.004 , respectively. For $B o_{v d w}=0$ and 20, the corrected $\xi$ is very close to the predictor. For $B o_{v d w}=50$ and 100 , the corrected $\xi$ is rather small, because the particles are collapsed together at defluidization. Therefore, it is reasonable to assume that the simulations are performed with an appropriate $\xi$ this time. Comparison of Figures 8 and 9 clearly demonstrates that for a realistic prediction of nanoparticle fluidization, both the adhesive contact model and reduced drag force should be considered. 

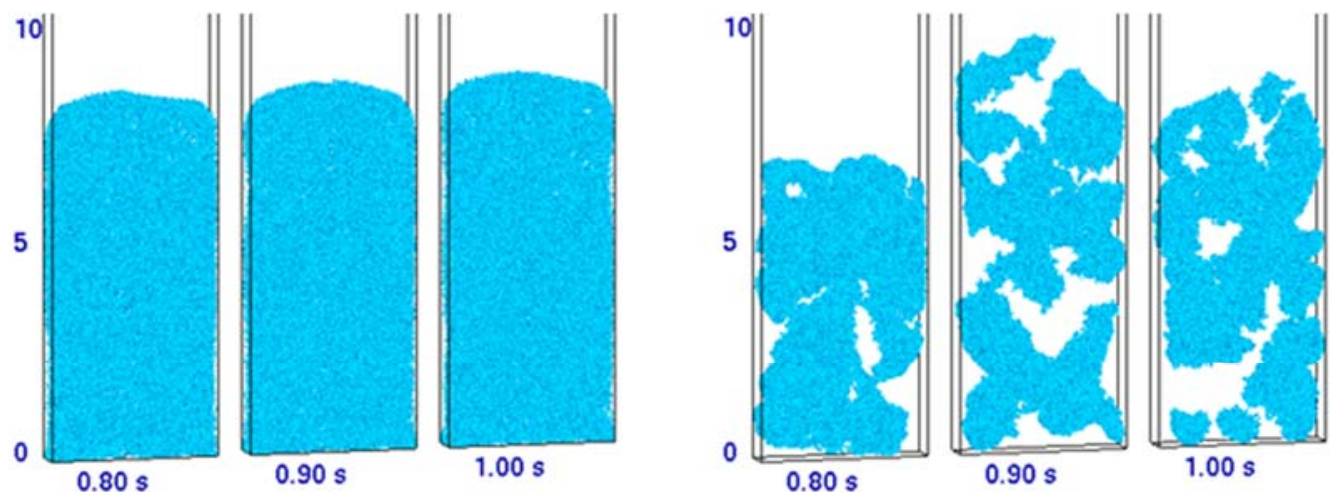

(a)

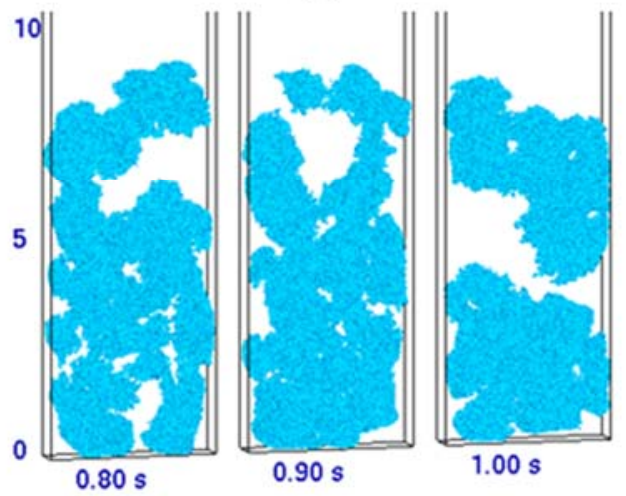

(c)

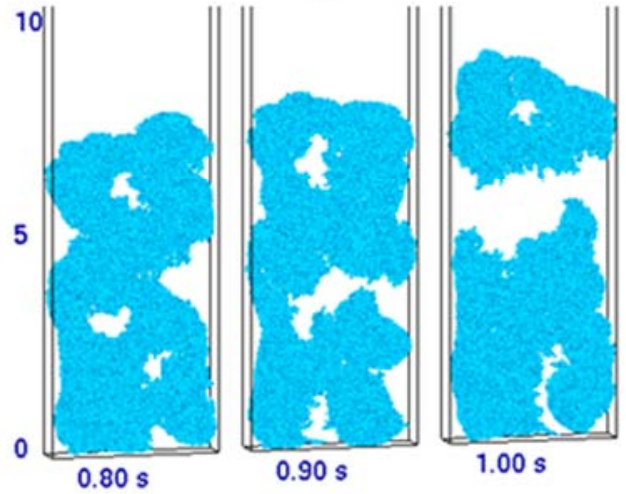

(d)

Figure 8 Snapshots of particle flow patterns under $B o_{v d w}=0,20,50$, and 100 , respectively. The drag force scale factor is 0.2 for all cases. 

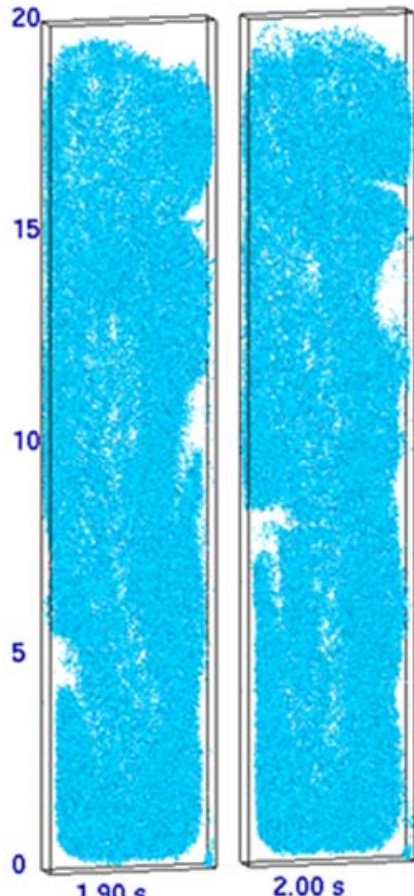

(a)

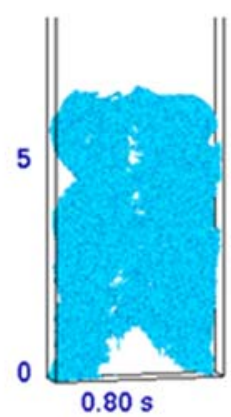

(a)
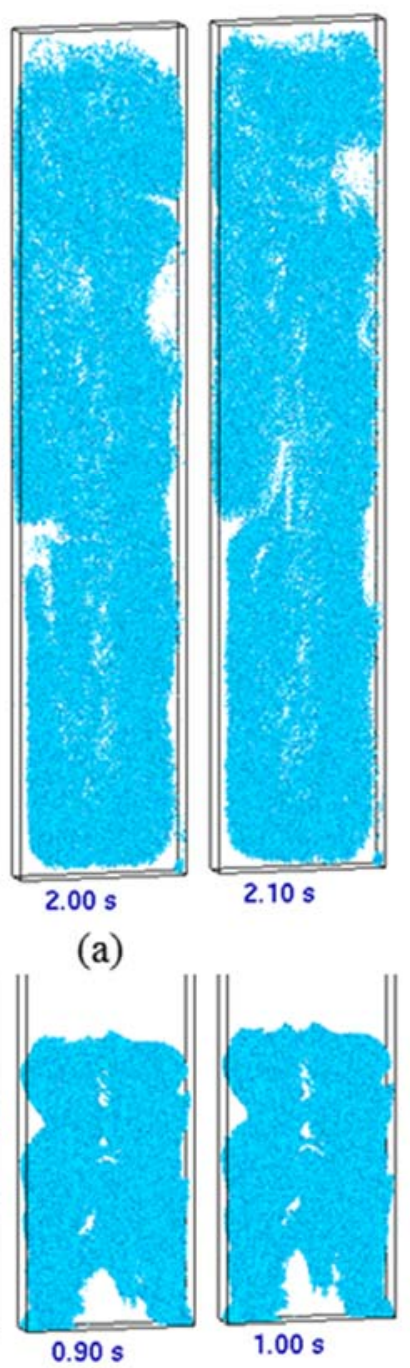

(c)
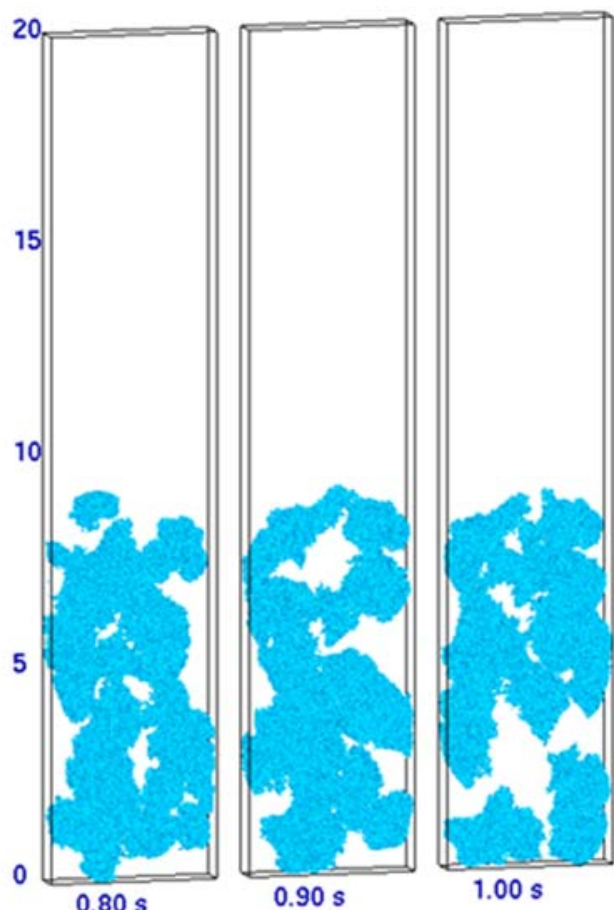

(b)
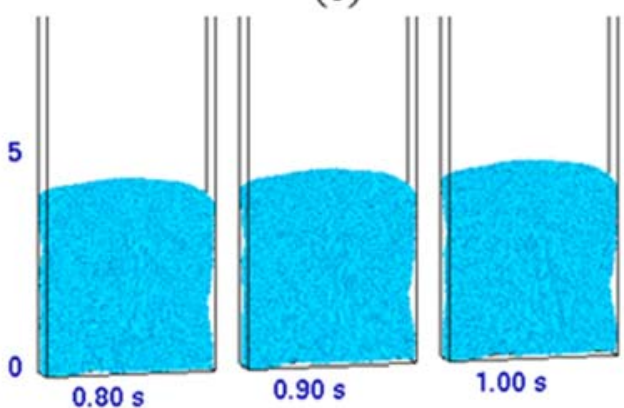

(d)

Figure 9 Snapshots of particle flow patterns under $B o_{v d w}=0,20,50$, and 100 , respectively. The drag force scale factor is $0.60,0.22,0.13$, and 0.04 .

The qualitative mechanisms can be revealed from the current predictions. The case of $B o_{v d w}=0$ represents an almost uniform fluid-like regime or APF type fluidization, where the bed expansion ration is approximately 5. The case of $B o_{v d w}=20$ represents a bubbling regime or ABF type fluidization, where the bubbles occur and the bed expansion ration is approximate 2 . For the cases with $B o_{v d w}=$ 50 and 100 , the bed makes the transition to a fixed bed regime. This is reasonable, because the minimum fluidization velocity increases with increasing particle cohesive force.

Further information can be handily extracted, with examples of the pressures and gas velocities presented here. The idea bed pressure drop is $5.1 \mathrm{~Pa}$ calculated based on the bed weight. The vertical profile of the time-averaged pressure in Figure 10a shows that the pressure decreases linearly from $\sim 5$ Pa to $0 \mathrm{~Pa}$ along the bed height, and the APF type fluidization has smallest pressure gradient. The variation of a local pressure with time in Figure $10 \mathrm{~b}$ shows that the pressure is smooth at $B o_{v d w}=$ 0,50 , and 100, while it fluctuates between $1.5 \mathrm{~Pa}$ and 3.0 Pa at $B o_{v d w}=20$. 
Figure 11 shows instantaneous fluidization patterns with gas volume fraction and gas velocity, with a zoomed in view shown in Figure 12. It is shown that at $B o_{v d w}=0$ the bed expands relatively uniformly, but it is still not completely uniform. At $B o_{v d w}=20$ the gas flow is not uniform and at some bubble zones the gas velocity can exceed $10 \mathrm{~cm} / \mathrm{s}$, which would lead to reduced mass transfer between gas and solid phase. This detailed information can be used to further improve understanding of nanoparticle fluidized beds in future studies.
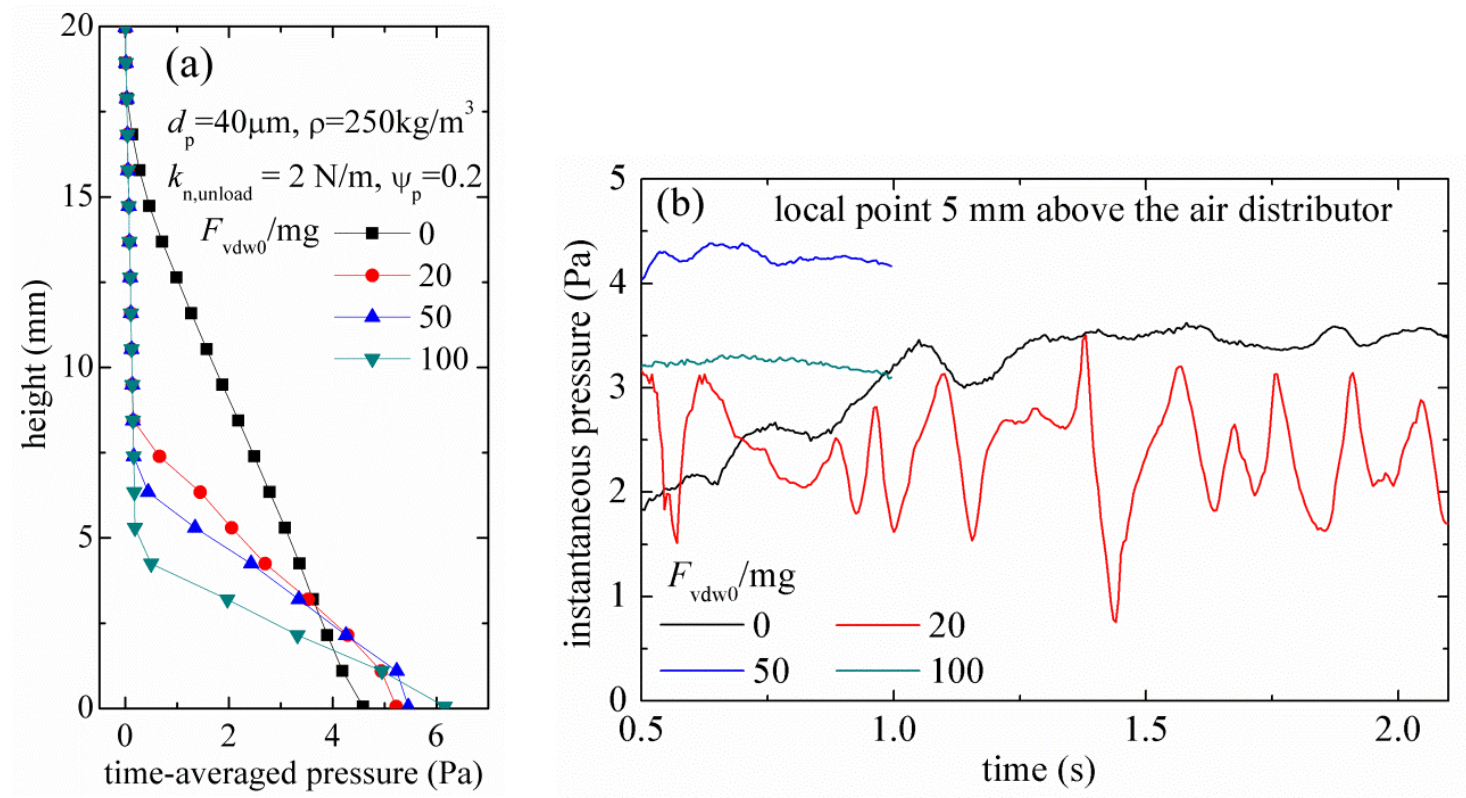

Figure 10 Pressure signals under different cohesive forces. (a) vertical profile of time-averaged pressure; (b) variation of pressure at $5 \mathrm{~mm}$ above the distributor with time. The cases of under $B o_{v d w}=$ 50 and 100 are performed for 1 second duration since they are close to defluidization.

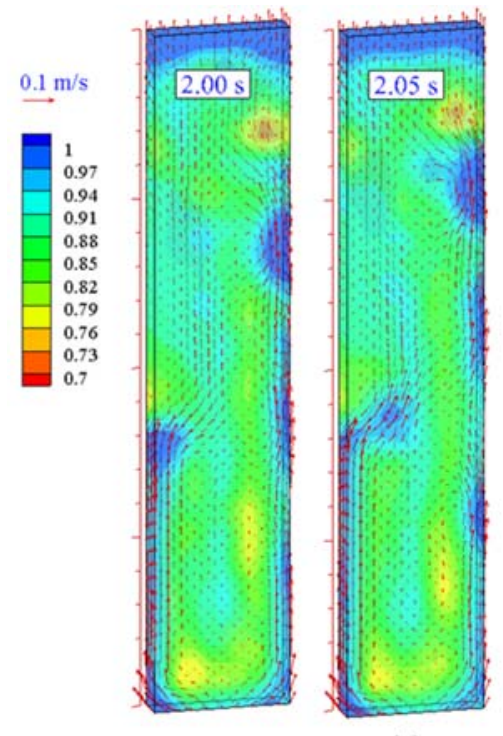

(a)

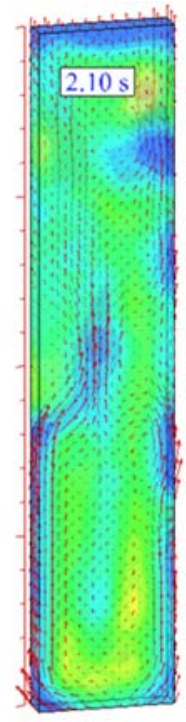

(a)
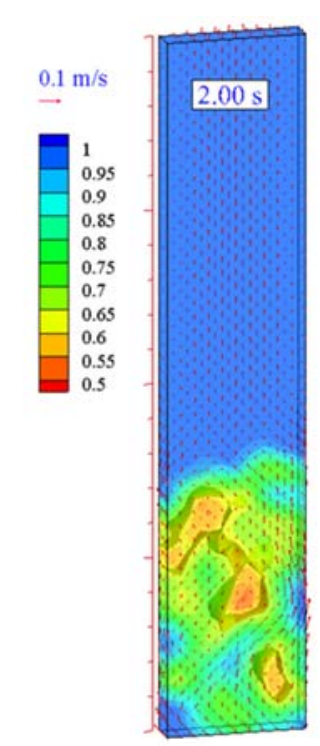

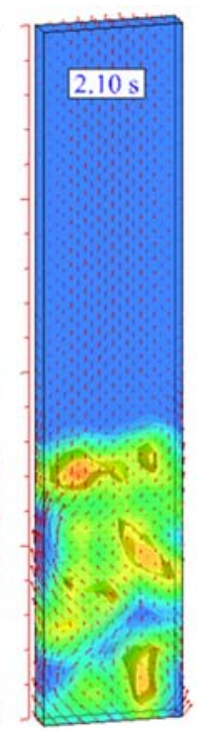

(b)

Figure 11 Flow patterns with gas volume fraction and gas velocity at different times for the case of (a)

$$
B o_{v d w}=0 \text {, and (b) } B o_{v d w}=20 \text {. }
$$




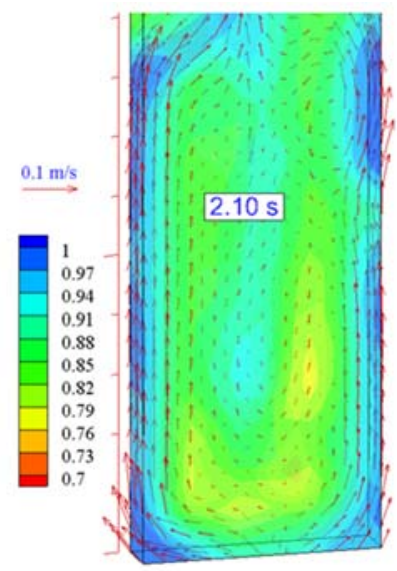

(a)

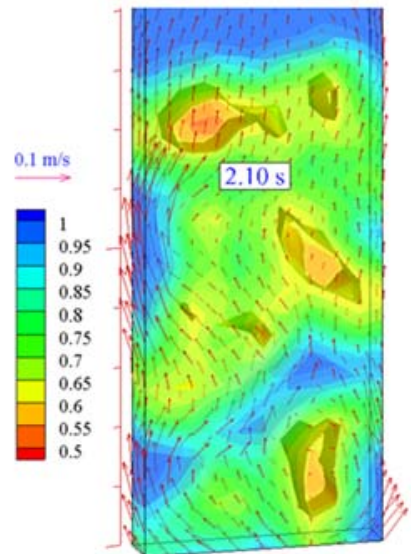

(b)

Figure 12 Zoom-in view of distribution of gas volume fraction and gas velocity for the case of (a)

$$
B o_{v d w}=0 \text {, and (b) } B o_{v d w}=20 \text {. }
$$

\section{Conclusions}

A model is proposed for simulating nanoparticle agglomerate fluidization, which is a combination of the conventional CFD-DEM model, an adhesive contact model and a drag force scale method. The novelty is that we base our model on simple agglomerates, the building blocks of the larger complex agglomerates encountered in a fluidized bed.

The current model is tested for different cases, including the normal impact, response of angle, and fluidization. It predicts that the particles bounce/stick behavior depends on the cohesive force, stiffness and plasticity. The response of angle of a particle assembly increases with increasing cohesive force and has a relation with the critical velocity. The fluidized bed shows subsequently a uniform fluid-like regime, a bubbling regime, and defluidization, respectively, with increasing particle cohesive force.

In this study, the drag force is scaled by a factor based on the agglomerate size. We show that this has an important effect on the fluidized bed hydrodynamics. The current version of the method is based on an average agglomerate size, assuming agglomerates are homogenous, spherical, and impermeable. We plan to study a further refined version in the future.

\section{Acknowledgments}

We would like to acknowledge the financial support for this study by the National Nature Science Foundation of China (51306035) and the ERC under the European Union's 7th Framework Programme (FP/2007-2013)/ERC Grant (279632). We thank Andrea Fabre, Wenjie Jin and Lilian de Martín for discussion during the model development.

\section{Appendix A}

Algorithm of search of particle contacts

For each particle $P[i]$ 
If "P[i] has contacted particles" AND "P[i] is not included in any contact list" Call Function: search contacts of $P[i]$

End for

End If

\section{Function: search contacts of $P[i]$}

Clear a stack data structure

Push P[i] into the stack

Put $P[i]$ in contact list [i], and mark P[i] as contacted particle

Line 4

Pop up a particle $P[j]$ from the stack

For each contact with $P[j]$

If it is not included in any contact list

Push it into the stack

Put it in contact list [i], and mark it as a contact particle

End for

End If

If stack is not empty, go back to Line 4; else it is done

\section{Appendix B}

Averaged agglomerate properties. $N_{p}$ is the particle number in an agglomerate and $d_{a g g}$ is the agglomerate.

\begin{tabular}{ccccc}
\hline \multicolumn{5}{c}{$\xi=0.20$} \\
& $B o_{v d w}=0$ & $B o_{v d w}=20$ & $B o_{v d w}=50$ & $B o_{v d w}=100$ \\
\hline$N_{p}$ & 5.9 & 21.4 & 36.7 & 196.7 \\
$d_{a g g}(\mu \mathrm{m})$ & 293 & 960 & 2149 & 3783 \\
\hline \multicolumn{5}{c}{} \\
\hline$N_{p}$ & $\xi=0.60$ & $\xi=0.22$ & $\xi=0.13$ & $\xi=0.04$ \\
$d_{a g g}(\mu \mathrm{m})$ & $19 o_{v d w}=0$ & $B o_{v d w}=20$ & $B o_{v d w}=50$ & $B o_{v d w}=100$ \\
\hline
\end{tabular}

\section{References}

Antonyuk, S., Khanal, M., Tomas, J., Heinrich, S., Morl, L., 2006. Impact breakage of spherical granules: Experimental study and DEM simulation. Chemical Engineering and Processing 45, 838-856.

Bahramian, A., Ostadi, H., Olazar, M., 2013. Evaluation of Drag Models for Predicting the Fluidization Behavior of Silver oxide Nanoparticle Agglomerates in a Fluidized Bed. Industrial \& Engineering Chemistry Research 52, 7569-7578.

de Martín, L., Bouwman, W.G., van Ommen, J.R., 2014a. Multidimensional Nature of Fluidized Nanoparticle Agglomerates. Langmuir 30, 12696-12702.

de Martín, L., Fabre, A., van Ommen, J.R., 2014b. The fractal scaling of fluidized nanoparticle agglomerates. Chemical Engineering Science 112, 79-86.

de Martín, L., van Ommen, J.R., 2013. A model to estimate the size of nanoparticle agglomerates in gassolid fluidized beds. Journal of Nanoparticle Research 15, 2055.

Deen, N.G., Annaland, M.V., Van der Hoef, M.A., Kuipers, J.A.M., 2007. Review of discrete particle modeling of fluidized beds. Chemical Engineering Science 62, 28-44. 
Galvin, J.E., Benyahia, S., 2014. The Effect of Cohesive Forces on the Fluidization of Aeratable Powders. AIChE Journal 60, 473-484.

Geldart, D., Abdullah, E.C., Hassanpour, A., Nwoke, L.C., Wouters, I., 2006. Characterization of powder flowability using measurement of angle of repose. China Particuology 4, 104-107.

Gundogdu, O., Jenneson, P.M., Tuzun, U., 2007. Nano particle fluidisation in model 2-D and 3-D beds using high speed X-ray imaging and microtomography. Journal of Nanoparticle Research 9, 215-223. Hakim, L.F., Portman, J.L., Casper, M.D., Weimer, A.W., 2005. Aggregation behavior of nanoparticles in fluidized beds. Powder Technology 160, 149-160.

He, Y.R., Wang, T.Y., Deen, N., Annaland, M.V., Kuipers, H., Wen, D.S., 2012. Discrete particle modeling of granular temperature distribution in a bubbling fluidized bed. Particuology 10, 428-437.

Huang, C., Wang, Y., Wei, F., 2008. Solids mixing behavior in a nano-agglomerate fluidized bed. Powder Technology 182, 334-341.

Johnson, K.L., Kendall, K., Roberts, A.D., 1971. Surface Energy and the Contact of Elastic Solids.

Proceedings of the Royal Society of London. Series A, Mathematical and Physical Sciences 324, 301-313.

Kendall, K., Weihs, T.P., 1992. Adhesion of nanoparticles within spray dried agglomerates. Journal of Physics D: Applied Physics 25, A3.

Kobayashi, T., Tanaka, T., Shimada, N., Kawaguchi, T., 2013. DEM-CFD analysis of fluidization behavior of Geldart Group A particles using a dynamic adhesion force model. Powder Technology 248, 143-152. Lepek, D., Valverde, J.M., Pfeffer, R., Dave, R.N., 2010. Enhanced Nanofluidization by Alternating Electric Fields. AIChE Journal 56, 54-65.

Li, S., Marshall, J.S., Liu, G., Yao, Q., 2011. Adhesive particulate flow: The discrete-element method and its application in energy and environmental engineering. Progress in Energy and Combustion Science 37, 633-668.

Li, T., Pougatch, K., Salcudean, M., Grecov, D., 2008. Numerical simulation of horizontal jet penetration in a three-dimensional fluidized bed. Powder Technology 184, 89-99.

Liu, D.Y., Bu, C.S., Chen, X.P., 2013. Development and test of CFD-DEM model for complex geometry: A coupling algorithm for Fluent and DEM. Computers \& Chemical Engineering 58, 260-268.

Luding, S., 2008. Cohesive, frictional powders: Contact models for tension. Granular Matter 10, 235-246. Luo, K., Yang, S., Fang, M., Fan, J., Cen, K., 2014. LES-DEM investigation of the solid transportation mechanism in a 3-D bubbling fluidized bed. Part I: hydrodynamics. Powder Technology 256, 385-394. Mallouppas, G., van Wachem, B., 2013. Large Eddy Simulations of turbulent particle-laden channel flow. International Journal of Multiphase Flow 54, 65-75.

Marshall, J.S., 2009. Discrete-element modeling of particulate aerosol flows. Journal of Computational Physics 228, 1541-1561.

Matsuda, S., Hatano, H., Muramoto, T., Tsutsumi, A., 2004. Modeling for size reduction of agglomerates in nanoparticle fluidization. AIChE Journal 50, 2763-2771.

McKeen, T., Pugsley, T., 2003. Simulation and experimental validation of a freely bubbling bed of FCC catalyst. Powder Technology 129, 139-152.

Motlagh, A.H.A., Grace, J.R., Salcudean, M., Hrenya, C.M., 2014. New structure-based model for Eulerian simulation of hydrodynamics in gas-solid fluidized beds of Geldart group " $\mathrm{A}$ " particles. Chemical Engineering Science 120, 22-36.

Quevedo, J.A., Omosebi, A., Pfeffer, R., 2010. Fluidization enhancement of agglomerates of metal oxide nanopowders by microjets. AIChE Journal 56, 1456-1468.

Raichman, Y., Kazakevich, M., Rabkin, E., Tsur, Y., 2006. Inter-nanoparticle bonds in agglomerates studied by nanoindentation. Advanced Materials 18, 2028-2030.

Salameh, S., Scholz, R., Seo, J.W., Mädler, L., 2014. Contact behavior of size fractionated TiO2

nanoparticle agglomerates and aggregates. Powder Technology 256, 345-351.

Schilde, C., Kwade, A., 2012. Measurement of the micromechanical properties of nanostructured aggregates via nanoindentation. Journal of Materials Research 27, 672-684.

Seo, M.W., Guahk, Y.T., Rho, N.S., Yoon, S.J., Ra, H.W., Koo, G.H., Kim, Y.K., Kim, J.H., Lee, J.G., Kim, S.D., 2014. Gasification Characteristics of Rapid Thermal Pyrolyzer Residue in a Fluidized Bed Reactor. Energy \& Fuels 28, 2984-2992. 
Tamadondar, M.R., Zarghami, R., Tahmasebpoor, M., Mostoufi, N., 2014. Characterization of the bubbling fluidization of nanoparticles. Particuology 16, 75-83.

Tomas, J., 2007. Adhesion of ultrafine particles - A micromechanical approach. Chemical Engineering Science 62, 1997-2010.

Tsuji, Y., Kawaguchi, T., Tanaka, T., 1993. Discrete particle simulation of two-dimensional fluidized bed. Powder Technology 77, 79-87.

Valverde, J.M., Castellanos, A., 2008. Fluidization of nanoparticles: A simple equation for estimating the size of agglomerates. Chemical Engineering Journal 140, 296-304.

van Ommen, J.R., Valverde, J.M., Pfeffer, R., 2012. Fluidization of nanopowders: a review. Journal of Nanoparticle Research 14, 737.

van Wachem, B., Sasic, S., 2008. Derivation, simulation and validation of a cohesive particle flow CFD model. AIChE Journal 54, 9-19.

van Wachem, B.G.M., 2013. MultiFlow, http://www.multiflow.org/.

van Wachem, B.G.M., van der Schaaf, J., Schouten, J.C., Krishna, R., van den Bleek, C.M., 2001.

Experimental validation of Lagrangian-Eulerian simulations of fluidized beds. Powder Technology 116, 155-165.

Wall, S., John, W., Wang, H.C., Goren, S.L., 1990. Measurements of kinetic-energy loss for particles impacting surfaces. Aerosol Science and Technology 12, 926-946.

Walton, O.R., Braun, R.L., 1986. Stress calculations for assemblies of inelastic speres in uniform shear. Acta Mechanica 63, 73-86.

Wang, J.W., van der Hoef, M.A., Kuipers, J.A.M., 2011. The role of scale resolution versus inter-particle cohesive forces in two-fluid modeling of bubbling fluidization of Geldart A particles. Chemical Engineering Science 66, 4229-4240.

Wang, S., Lu, H., Gao, J.M., Lu, H.L., Liu, G.D., Xu, P.F., He, Y.R., 2013. CFD simulation of gas-solid flow with a cluster structure-dependent drag coefficient model in circulating fluidized beds. Applied Mathematical Modelling 37, 8179-8202.

Wang, X.S., Palero, V., Soria, J., Rhodes, M.J., 2006. Laser-based planar imaging of nano-particle fluidization: Part I - determination of aggregate size and shape. Chemical Engineering Science 61, 54765486.

Wang, X.S., Rahman, F., Rhodes, M.J., 2008. Application of discrete element method simulation for studying fluidization of nanoparticle agglomerates. Canadian Journal of Chemical Engineering 86, 514-

522.

Wang, Y., Gu, G., Wei, F., Wu, J., 2002. Fluidization and agglomerate structure of SiO2 nanoparticles. Powder Technology 124, 152-159.

Yang, S.L., Luo, K., Fang, M.M., Zhang, K., Fan, J.R., 2014. Parallel CFD-DEM modeling of the hydrodynamics in a lab-scale double slot-rectangular spouted bed with a partition plate. Chemical Engineering Journal 236, 158-170.

Ye, M., van der Hoef, M.A., Kuipers, J.A.M., 2004. A numerical study of fluidization behavior of Geldart A particles using a discrete particle model. Powder Technology 139, 129-139.

Zeidan, E.S.B., Okasha, F.M., 2014. Controlling the freeboard temperature applying a novel design of fluidized bed. Journal of the Taiwan Institute of Chemical Engineers 45, 1347-1353.

Zhong, W., Xiong, Y., Yuan, Z., Zhang, M., 2006. DEM simulation of gas-solid flow behaviors in spout-fluid bed. Chemical Engineering Science 61, 1571-1584.

Zhu, C., Liu, G., Yu, Q., Pfeffer, R., Dave, R.N., Nam, C.H., 2004. Sound assisted fluidization of nanoparticle agglomerates. Powder Technology 141, 119-123.

Zhu, H.P., Zhou, Z.Y., Yang, R.Y., Yu, A.B., 2007. Discrete particle simulation of particulate systems:

Theoretical developments. Chemical Engineering Science 62, 3378-3396. 